\title{
Parental perception of weight and weight-related behaviour in 2- to 4-year-old children in the eastern part of the Netherlands
}

\author{
H. N. Bossink-Tuna • M. P. L'Hoir • M. Beltman • \\ M. M. Boere-Boonekamp
}

Received: 16 May 2008 / Accepted: 19 June 2008 / Published online: 29 July 2008

(C) The Author(s) 2008

\begin{abstract}
Parental perception of weight status and weightrelated behaviour of their toddler was determined through a questionnaire survey in child health care centres (CHCs). Complete data on weight, length, sex and age were available for 635 of 682 children (93.1\%). The median age of the children was 37.0 months (range 24-56 months). Of all 635 children, $76.5 \%$ were normal weight, $16.2 \%$ underweight and $7.2 \%$ overweight. Parents' perception of the weight of their child compared with their peers was moderately related to the actual weight status. Of the parents of overweight and underweight children, $87.0 \%$ and $89.3 \%$, respectively, were not concerned. Only the parents' perception of the amount of food eaten by their child was significantly related to the weight status. The primary goal of CHC workers should be to create parental awareness in case of their child being overweight or underweight and to support them in accomplishing a healthy lifestyle.
\end{abstract}

Keywords Preschool children - Perception - Obesity .

Overweight · Underweight

\section{Introduction}

The prevention and treatment of childhood overweight is one of the most important public health challenges. Childhood overweight is partially environmentally influenced,

H. N. Bossink-Tuna $\cdot$ M. M. Boere-Boonekamp $(\bowtie)$

Department of Management and Governance,

University of Twente,

P.O. Box 217, 7500 AE Enschede, The Netherlands

e-mail: m.m.boere-boonekamp@utwente.nl

M. P. L'Hoir • M. Beltman

TNO, Quality of Life,

Leiden, The Netherlands although it remains difficult to disentangle its determinants and risk factors. Therefore, it is worthwhile to identify environmental factors that can be influenced for prevention or treatment purposes [10].

The prevalence of overweight and obesity in the Netherlands is increasing at an even faster rate than previously, and the prevalence of overweight in Dutch children aged 0-20 years doubled from 1980 to 1997 [16].

Parents are of key importance in the prevention of childhood overweight. To involve parents in the prevention and treatment of overweight and obesity in their children successfully, awareness is of the utmost importance. Admitting that their child is at risk is an important prerequisite for the motivation to act [19].

The first step in promoting a healthy lifestyle and a healthy body weight among preschool-aged children might be creating awareness amongst parents that obesity is a health problem. Although there is no direct evidence that increasing parents' awareness would prevent overweight and obesity in children, there is evidence that it can prevent risky overweight-increasing behaviour among children and adolescents [23]. Parents do not consult growth charts to determine whether their child is overweight. Instead, they might notice when a child becomes inactive or suffers from teasing by other children.

Parents may tend to define obesity as a condition accompanied by severe physical impairment, especially compromised mobility. They may also believe that a child's size is inherited and that the child will eventually shed excess weight with age [18].

Between 1980 and 1997, in the Netherlands, the prevalence of serious underweight in 2-6-year-old children increased and in older children it decreased. There was also a rise in the variation of the weights at any give age, possibly reflecting more marked health differences [4]. 
Underweight is related to several health risks. In the western world, it is a manifestation of a spectrum of disorders, coeliakie being the most important in preschool children. In developing countries, underweight is usually caused by undernutrition and, together with wasting and stunting, it affects about 200 million children under the age of 5 years [21].

Parents who do not admit weight problems in their children, either under- or overweight, are less likely to take steps to change their children's lifestyles [6]. Summarising, parental behaviour change might be easier when they are aware of the overweight (or underweight) status of their child, perceive overweight as a problem that needs to be prevented and, subsequently, are informed on how to prevent it and have appropriate skills to change their own behaviour.

This study was conducted to determine whether parents have the correct perception of their child's weight status and weight-related behaviour and the level of concern they experience about their child's (future) weight.

\section{Methods}

In a cross-sectional survey, an anonymous self-administered questionnaire was completed by 682 parents of children $2-$ 4 years of age in a partly urban but mostly rural part of the Netherlands (Hengelo and broad environment) who visited the child health care centres (CHCs) of the Organization of Home Care Carint in a 6-week period (from 18 April 2006 to 2 June 2006). The weight and length of the children were measured by trained CHC staff on calibrated measurement instruments, to the nearest $0.1 \mathrm{~kg}$ and $0.1 \mathrm{~cm}$ precision, without shoes and in underwear only. The registration of general characteristics comprised: gender and age (in months) of the child, and country of birth (Netherlands/ Other), educational level (low, intermediate, high) and selfreported length (in $\mathrm{cm}$ ) and weight (in $\mathrm{kg}$ ) of the mother and father.

\section{Questionnaire}

In a written questionnaire, participants responded to the following items using a five-point Likert scale (range 'disagree a lot' to 'agree a lot'): "I am worried my child is overweight right now"; "I am worried my child will become overweight"; "I am worried my child is underweight right now" [5]. Responses were dichotomised to 'agree' or 'disagree,' with the neutral answer classified as 'disagree.'

Participants also rated their child on five-point scales 'in comparison with other children his/her age' with regard to weight ('much thinner' to 'much more overweight'), healthiness of diet ('much less healthy' to 'much more healthy'), amount of food eaten ('eats much less' to 'eats much more') and activity level ('much less active' to 'much more active') [5]. These variables were reduced to three categories ('less,' 'about the same' or 'more'). All participants were also categorised as two groups: Dutch and non-Dutch. The non-Dutch group included three ethnic groups: Turkish, Moroccans and others.

\section{Data analysis}

The body mass index (BMI) of the children was calculated, and they were classified as: (i) severe underweight and underweight (together 'underweight'), (ii) normal weight and (iii) overweight and obesity (together 'overweight'), based on internationally accepted age- and sex-specific cutoff points $[4,7]$. The BMI was also calculated for the parents, and they were categorised as normal weight $(\mathrm{BMI}<$ $25)$ and overweight $(B M I \geq 25)$. Bivariate relationships between categorical variables were examined using $\chi^{2}$ tests or Fisher's exact test, where the expected cell count was less than 5 in more than $20 \%$ of cells. A logistic regression analysis was done with the $z$-score of the BMI of the child as dependent variables. Statistical analyses were carried out using SPSS v12.0 software.

\section{Results}

Complete data on weight, length, sex and age were available for 635 of 682 children (93.1\%). Descriptive characteristics of the children and their parents classified according to the weight category of the child are presented in Table 1. Of all 635 children, $76.5 \%$ were normal weight, $16.2 \%$ underweight (including 3.0\% with severe underweight; $n=19$ ) and $7.2 \%$ overweight (including $0.8 \%$ with obesity; $n=5$ ). The age distribution of the children showed a peak at the ages of 24, 36 and 45 months, representing regular CHC consultation moments; the median age of the children was 37.0 months (range 24-56 months). There was a significant difference in weight status between boys and girls. The prevalence of underweight as well as the prevalence of overweight was higher in girls than in boys. Furthermore, the children of Dutch mothers were more often underweight, while the children of non-Dutch mothers were more often overweight.

Most of the mothers $(92.3 \%)$ and fathers $(93.0 \%)$ were born in the Netherlands. Fifty-seven percent of the mothers and $48.8 \%$ of the fathers had an intermediate education. Fathers reported overweight more often $(53.3 \%)$ than mothers $(35.9 \%)$.

We compared parents with overweight, underweight and normal weight children to examine their perception of the 
Table 1 General characteristics of the 635 children 2 to 4 years of age and their parents according to the weight status category of the child

\begin{tabular}{|c|c|c|c|c|c|}
\hline & \multicolumn{5}{|c|}{ Weight category } \\
\hline & All $(n=635)^{\mathrm{a}}$ & Underweight $(n=103)^{\mathrm{a}}$ & Normal $(n=486)^{\mathrm{a}}$ & Overweight $(n=46)^{\mathrm{a}}$ & $p$-value \\
\hline \multicolumn{6}{|c|}{ Gender of child } \\
\hline Boys & 334 & $46(13.8)$ & $270(80.8)$ & $18(5.4)$ & \multirow[t]{2}{*}{0.022} \\
\hline Girls & 301 & $57(18.9)$ & $216(71.8)$ & $28(9.3)$ & \\
\hline \multicolumn{6}{|l|}{ Age in years } \\
\hline 2 & 206 & $30(14.6)$ & $163(79.1)$ & $13(6.3)$ & \multirow[t]{3}{*}{0.741} \\
\hline 3 & 414 & $71(17.1)$ & $312(75.4)$ & $31(7.5)$ & \\
\hline 4 & 15 & $2(13.3)$ & $11(73.3)$ & $2(13.3)$ & \\
\hline \multicolumn{6}{|c|}{ Country of birth of mother } \\
\hline Dutch & 575 & $101(17.6)$ & $435(75.7)$ & $39(6.8)$ & \multirow[t]{2}{*}{0.013} \\
\hline Non-Dutch & 48 & $2(4.2)$ & $39(81.3)$ & $7(14.6)$ & \\
\hline \multicolumn{6}{|c|}{ Country of birth of father } \\
\hline Dutch & 556 & $88(15.8)$ & $427(76.8)$ & $41(7.4)$ & \multirow[t]{2}{*}{0.449} \\
\hline Non-Dutch & 42 & $8(19.0)$ & $29(69.0)$ & $5(11.9)$ & \\
\hline \multicolumn{6}{|c|}{ Maternal education ${ }^{\mathrm{b}}$} \\
\hline Low & 64 & $12(18.8)$ & $50(78.1)$ & $2(3.1)$ & \multirow[t]{3}{*}{0.130} \\
\hline Intermediate & 350 & $62(17.7)$ & $267(76.3)$ & $21(6.0)$ & \\
\hline High & 200 & $29(14.5)$ & $149(74.5)$ & $22(11.0)$ & \\
\hline \multicolumn{6}{|c|}{ Paternal education ${ }^{\mathrm{b}}$} \\
\hline Low & 74 & $14(18.9)$ & $55(74.3)$ & $5(6.8)$ & \multirow[t]{3}{*}{0.701} \\
\hline Intermediate & 290 & $51(17.6)$ & $218(75.2)$ & $21(7.2)$ & \\
\hline High & 230 & $31(13.5)$ & $180(78.3)$ & $19(8.3)$ & \\
\hline
\end{tabular}

${ }^{\text {a }}$ May not count towards totals because of missing data

${ }^{\mathrm{b}}$ Lower=technical and vocational training; Intermediate=vocational training and advanced secondary education; Higher=vocational education (college) and university

child's weight, their level of concern about the child's current and future weight, and their perception of the healthiness of the diet, physical activity level and the amount eaten by their child in comparison with their peers (Table 2). There was a significant difference in the parents' perception about the weight of their child compared with their peers between the parents of overweight, normal weight and underweight children. Of the parents of underweight children, $54.4 \%$ perceived their child as thinner versus $13.5 \%$ and $2.2 \%$ of the parents of normal weight and overweight children, respectively. Of the parents of overweight children, $37.8 \%$ perceived their child as more overweight versus $3.7 \%$ and $0 \%$ of the parents of normal weight and underweight children, respectively. Of the parents of overweight children, $87 \%$ were not concerned and $40 \%$ were not concerned about future overweight either. Of the parents of underweight children, $89.3 \%$ were not concerned about their child's underweight. There was no difference in the perception of the healthiness of the diet and the activity level between the parents of overweight, normal weight and underweight children. Of the parents with underweight children, $25.5 \%$ reported that their child ate less; of the parents with overweight children, $28.3 \%$ reported that their child ate more compared with their peers $(p=0.000)$.
Figure 1 shows the distribution of the child BMI $z$-scores according to the level of parental concern about current overweight. The height of the box (i.e. the difference between the third and first quartile) is about equal for the two groups, indicating that the spread of the middle $50 \%$ of the scores does not differ much among the groups. There was a significant difference in the median BMI $z$-score between the concerned and not concerned groups (concerned 0.47; not concerned -0.18; Mann-Whitney $U$-test $p=0.007$ ), indicating that, for the group of children with concerned parents, the BMI score was, on average, higher than for the group of children whose parents were not concerned. The fact that the median $z$-score was positive for the first group, and negative for the latter, means that more than $50 \%$ of the children with concerned parents have a BMI value above the general mean BMI, and that less than $50 \%$ of the children with not concerned parents have a BMI value above the general mean BMI.

Comparable results were found for the distribution of the child BMI $z$-scores according to the level of parental concern about future overweight. There was a significant difference in the median BMI $z$-score between the concerned and not concerned groups (concerned 0.04; not concerned -0.21 ; Mann-Whitney $U$-test $p=0.006$ ) (boxand-whiskerplot not presented). 
Table 2 Responses to questionnaire items according to the child's weight status category

\begin{tabular}{|c|c|c|c|c|}
\hline \multirow[t]{2}{*}{ Questionnaire item } & \multicolumn{4}{|l|}{ Weight category } \\
\hline & Underweight $(n=103)^{\mathrm{a}}$ & Normal $(n=486)^{\mathrm{a}}$ & Overweight $(n=46)^{\mathrm{a}}$ & $p$-value \\
\hline \multicolumn{5}{|c|}{ Perception of child's weight compared with peers } \\
\hline Thinner & $56(54.4)$ & $65(13.5)$ & $1(2.2)$ & \multirow[t]{3}{*}{0.000} \\
\hline Similar & $47(45.6)$ & $400(82.8)$ & $27(60.0)$ & \\
\hline More overweight & $0(0)$ & $18(3.7)$ & $17(37.8)$ & \\
\hline \multicolumn{5}{|c|}{ Concerned that child is overweight now } \\
\hline Agree & $1(1.0)$ & $19(3.9)$ & $6(13.0)$ & \multirow[t]{2}{*}{0.003} \\
\hline Disagree & $102(99.0)$ & $466(96.1)$ & $40(87.0)$ & \\
\hline \multicolumn{5}{|c|}{ Concerned that child will become overweight } \\
\hline Agree & $23(22.3)$ & $194(40.2)$ & $27(60.0)$ & \multirow[t]{2}{*}{0.000} \\
\hline Disagree & $80(77.7)$ & $289(59.8)$ & $18(40.0)$ & \\
\hline \multicolumn{5}{|c|}{ Concerned that child is underweight now } \\
\hline Agree & $11(10.7)$ & $20(4.1)$ & $2(4.3)$ & \multirow[t]{2}{*}{0.025} \\
\hline Disagree & $92(89.3)$ & $463(95.9)$ & $44(95.7)$ & \\
\hline \multicolumn{5}{|c|}{ Perception of child's healthy diet compared with peers } \\
\hline More healthy & $14(13.7)$ & $81(16.7)$ & $11(23.9)$ & \multirow[t]{3}{*}{0.418} \\
\hline About the same & $84(82.4)$ & $395(81.4)$ & $34(73.9)$ & \\
\hline Less healthy & $4(3.9)$ & $9(1.9)$ & $1(2.2)$ & \\
\hline \multicolumn{5}{|c|}{ Perception of child's activity level compared with peers } \\
\hline More active & $36(35.0)$ & $177(36.5)$ & $14(30.4)$ & \multirow[t]{3}{*}{0.423} \\
\hline About the same & $64(62.1)$ & $304(62.7)$ & $31(67.4)$ & \\
\hline Less active & $3(2.9)$ & $4(0.8)$ & $1(2.2)$ & \\
\hline \multicolumn{5}{|c|}{ Perception of amount of food eaten by the child compared with peers } \\
\hline Eats more & $6(5.9)$ & $59(12.2)$ & $13(28.3)$ & \multirow[t]{3}{*}{0.000} \\
\hline About the same & $70(68.6)$ & $356(73.4)$ & $26(56.5)$ & \\
\hline Eats less & $26(25.5)$ & $70(14.4)$ & $7(15.2)$ & \\
\hline
\end{tabular}

${ }^{\text {a }}$ May not count towards totals because of missing data

Figure 2 shows the distribution of the child BMI $z$-scores according to the level of parental concern about underweight. There was no difference in the median BMI $z$-score between the concerned and not concerned groups (concerned -0.17 ; not concerned -0.13 ; Mann-Whitney $U$-test $p=0.754$ ).

The level of concern of parents of overweight $(n=46)$ and underweight $(n=106)$ children was not related to gender, age of the child or the country of birth, educational level and weight status of the father and mother.

A multivariate logistic regression analysis with $z$-scores of the BMI of the child as the dependent variable and the age of the child, gender, country of birth of the parents, education of parents, concern that the child is overweight now, concern that the child will become overweight in the future and perception of the child's weight compared with peers as independent variables showed that the parents' perception of their child's weight as compared with their peers was significantly related with concern about current overweight $(p=0.005)$ and concern that a child would become overweight in the future $(p=0.031)$.

\section{Discussion}

This study shows that $62 \%$ of the parents of overweight children and $46 \%$ of the parents of underweight children in the age group of 2 to 4 years estimated their children's weight status incorrectly. The perception of the healthiness of the diet and the physical activity level did not differ between the parents of overweight, normal weight and underweight children. Only the perceived amount of food eaten by their children differed significantly, but still just over one quarter of parents with underweight or overweight children reported that their child ate less respectively more compared with their peers

A strong feature of this study was the high response rate of $93 \%(n=635)$ on the questionnaire. Therefore, the results of the study are generalisable to the preschool population living in an eastern, mostly rural, part of the Netherlands. Another strong feature of the study is that the anthropometric data of the children were collected according to a uniform protocol, which makes the BMI data highly reliable. One of the limitations of the study was that the 


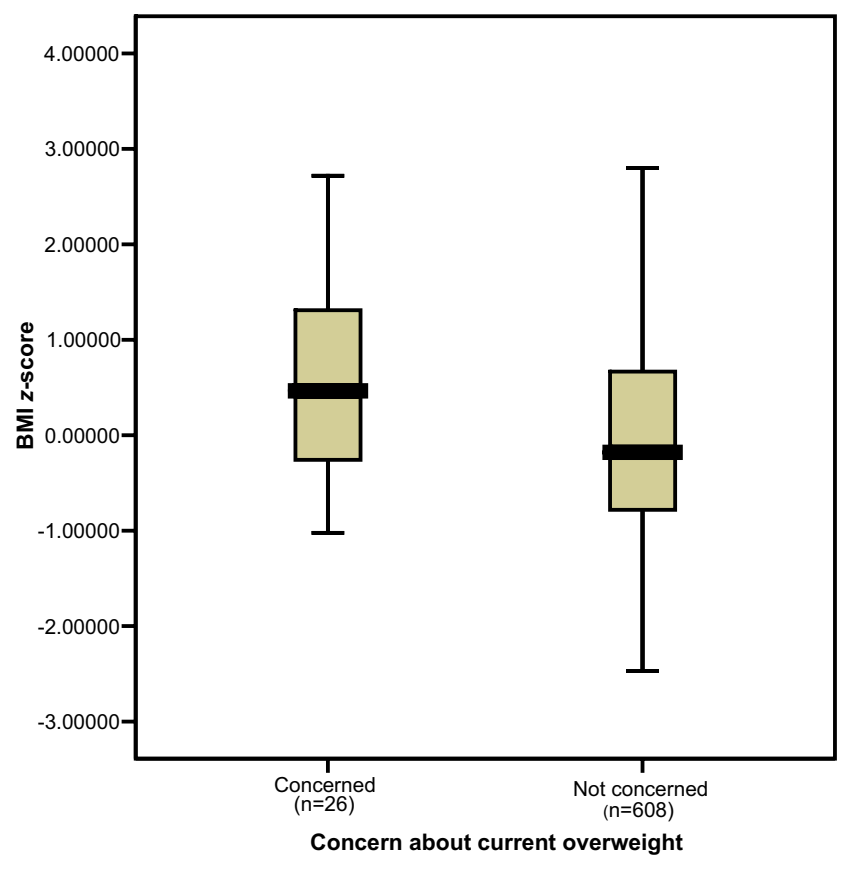

Fig. 1 Box-and-whisker plot of child body mass index (BMI) $z$-score by parental concern about current overweight. The bold line in the middle of the box shows the median value, which is significantly higher for the concerned versus the not concerned parents $(p=0.007)$. The top whisker of the box is the third quartile and the low whisker the first quartile

overweight prevalence figures of the parents (fathers: 53.3\%; mothers: $35.9 \%$ ) are based on self-reported anthropometric data, which are known to have restricted reliability [14]. The prevalence proved to be slightly lower than that reported in other Dutch studies, based on measured data (2005-2006: male: $57 \%$; female: $42 \%$ ) [25]. Finally, our choice to classify the neutral answers on the three questions on concern about the weight status as 'disagree' can be debated. However, it made the results comparable with those of other studies $[1,5]$.

In the study population, $7.2 \%$ of the preschool children were overweight and $16.2 \%$ were underweight. A comparable prevalence of overweight in preschoolers was found in other rural parts of the Netherlands [24], but in urban populations, a prevalence of $14-15 \%$ was found $[3,8,13$, 26, 27]. In 1997 in the Netherlands, according to the international criteria proposed by Cole et al. [7], the overweight prevalence was 7.4 to $9.7 \%$ and 8.2 to $12.3 \%$ in 2-4-year-old boys and girls, respectively; according to criteria proposed by van Buuren [4], the underweight prevalence for 2-6-year-old children was $16.2 \%$ (boys) and $15.0 \%$ (girls). In our study, girls and children of nonDutch parents were more often overweight. These findings were consistent with previous studies. According to a study of Fredriks et al., Turkish and Moroccan children are considerably more often overweight than Dutch children $[11,15]$.

Also, in 2006, a parallel cross-sectional study of school children in exactly the same area of the Netherlands showed that $17.2 \%$ of children $5-6$ years of age $(432 / 2,509)$ and $23.5 \%$ of children $10-11$ years of age $(376 / 1,597)$ were overweight [12]. It appears that a dramatic rise in the prevalence of overweight occurs in children after the preschool period.

Recognising a deviant weight status, at least in their own child, seems to be a universal problem for parents. Therefore, it is not surprising that almost $90 \%$ of parents were not concerned about the presence of underweight or overweight in their child. Even $40 \%$ of parents of overweight children were not concerned about future overweight. In the USA and Australia, even $70 \%$ [1] to $80 \%$ [5] of mothers of overweight children failed to perceive their child as overweight, especially mothers with a low level of education [1]. In Australia, only 5\% of mothers indicated concern about their child being overweight, while only $16 \%$ was worried that their child would become overweight in the future [5]. Studies from other countries have also shown that parents are neither concerned about nor sensitive to their children's overweight or obese status $[6,9,17,19,20$, 22]. In the Netherlands, there seems to be a little more awareness and concern compared to Australia and the

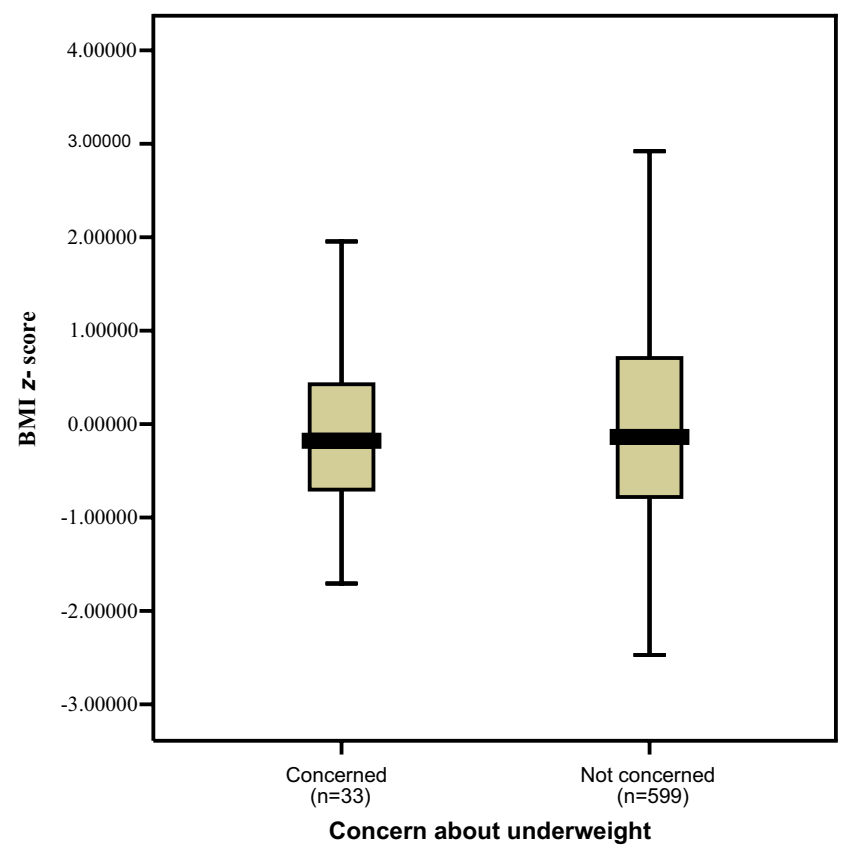

Fig. 2 Box-and-whisker plot of child BMI $z$-score by parental concern about underweight. The bold line in the middle of the box shows the median value, which was not different for the concerned versus the not concerned $(p=0.754)$. The top whisker of the box is the third quartile and the low whisker the first quartile 
USA. In the studies in those countries, however, much more overweight and obese fathers and mothers were included. This suggests that the normal perception has become a more 'overweight' perception, which is very worrisome.

To our knowledge, this is one of the first studies into parents' perception of the weight status of their preschool child that includes underweight as well, so the comparison of results across studies was not possible. Further studies are needed to establish the significance of the cut-off points for (severe) underweight in terms of sensitivity and specificity for the presence of specific disorders in Western countries.

Even parents who realise that they have an overweight or obese child may not know that obese children are more likely to become obese adults and have an increased risk of developing diabetes and heart disease. It appears that parents often believe that young children may outgrow their overweight. Recognition of overweight by parents and being concerned is an important step towards the process of the prevention, diagnosis and treatment of childhood obesity [2].

We conclude that overweight as well as underweight go largely unrecognised and parents fail to identify the future weight in their children correctly. When parents are not aware and concerned of their child's under- or overweight, we cannot expect them to change their childrearing or life style behaviour. The reasons for poor awareness might include denial, reluctance to admit a weight problem, or desensitisation to excess weight because being overweight has become normal. Parents may protect themselves by denying the problem. Overweight or obese parents have not been able to fight it, so why make a problem over it? This coping style might prevent the child from becoming depressed and prevent feelings of low self-esteem.

As public health policies try to increase parental awareness about preventing obesity, they can also help improve the recognition of childhood overweight. In future research, the underlying mechanisms for why parents do not recognise either overweight or underweight should be explored and how they are supported optimally in doing so. While informing parents about the weight of their child, the health care workers should stay alert in order to prevent an increase in anxiety in young parents. The side effect of too much attention could be that more children become underweight or develop feeding/eating problems. Finding a good balance is of utmost importance.

Acknowledgements We would like to thank all of the child health care workers in the study area for their contribution in the collection of the data.

Open Access This article is distributed under the terms of the Creative Commons Attribution Noncommercial License which per- mits any noncommercial use, distribution, and reproduction in any medium, provided the original author(s) and source are credited.

\section{References}

1. Baughcum AE, Chamberlin LA, Deeks CE et al (2000) Maternal perceptions of overweight preschool children. Pediatrics 106: $1380-1386$

2. Boa-Sorte N, Neri LA, Leite ME et al (2007) Maternal perceptions and self-perception of the nutritional status of children and adolescents from private schools. J Pediatr (Rio J) 83:349356

3. Boere-Boonekamp MM, L'Hoir MP, Beltman M et al (2008) Overweight and obesity in preschool children ( $0-4$ years): behaviour and views of parents. Ned Tijdschr Geneeskd 152: 324-330

4. van Buuren S (2004) Body-mass index cut-off values for underweight in Dutch children. Ned Tijdschr Geneeskd 148: 1967-1972

5. Campbell MW, Williams J, Hampton A et al (2006) Maternal concern and perceptions of overweight in Australian preschoolaged children. Med J Aust 184:274-277

6. Carnell S, Edwards C, Croker H et al (2005) Parental perceptions of overweight in 3-5 y olds. Int J Obes Relat Metab Disord 29: 353-355

7. Cole TJ, Bellizzi MC, Flegal KM et al (2000) Establishing a standard definition for child overweight and obesity worldwide: international survey. BMJ 320:1240-1243

8. Cornelisse-Vermaat CR, van den Brink HM (2007) Ethnic differences in lifestyle and overweight in the Netherlands. Obesity (Silver Spring) 15:483-493

9. Eckstein KC, Mikhail LM, Ariza AJ et al (2006) Parents' perceptions of their child's weight and health. Pediatrics 117: 681-690

10. Faith MS, Scanlon KS, Birch LL et al (2004) Parent-child feeding strategies and their relationships to child eating and weight status. Obes Res 12:1711-1722

11. Fredriks AM, Van Buuren S, Sing RA et al (2005) Alarming prevalences of overweight and obesity for children of Turkish, Moroccan and Dutch origin in The Netherlands according to international standards. Acta Pediatr 94:496-498

12. GGD Regio Twente (2006) Overweight facts. Home page at: http://www.twenteinbalans.nl/

13. GGD Rotterdam and Environment (2004) Youth monitor Rotterdam; research toddlers (in Dutch). GGD Rotterdam and Environment, Rotterdam

14. Gorber SC, Tremblay M, Moher D et al (2007) A comparison of direct vs. self-report measures for assessing height, weight and body mass index: a systematic review. Obes Rev 8:307326

15. Hirasing RA, Fredriks AM, van Buuren $S$ et al (2001) Increased prevalence of overweight and obesity in Dutch children, and the detection of overweight and obesity using international criteria and new reference diagrams. Ned Tijdschr Geneeskd 145:13031308

16. van den Hurk K, van Dommelen P, van Buuren S et al (2007) Prevalence of overweight and obesity in the Netherlands in 2003 compared to 1980 and 1997. Arch Dis Child 92:992-995

17. Jackson J, Strauss CCYD, Lee AA et al (1990) Parents' accuracy in estimating child weight status. Addict Behav 15:65-68

18. Jain A, Sherman SN, Chamberlin LA et al (2001) Why don't lowincome mothers worry about their preschoolers being overweight? Pediatrics 107:1138-1146 
19. Jansen W, Brug J (2006) Parents often do not recognize overweight in their child, regardless of their socio-demographic background. Eur J Public Health 16:645-647

20. Jeffrey AN, Voss LD, Metcalf BS et al (2005) Parents' awareness of overweight in themselves and their children: cross sectional study within a cohort (EarlyBird 21). BMJ 330:23-24

21. Nannan N, Norman R, Hendricks M et al (2007) Estimating the burden of disease attributable to childhood and maternal undernutrition in South Africa in 2000. S Afr Med J 97:733-739

22. Saxena S, Ambler G, Cole TJ et al (2004) Ethnic group differences in overweight and obese children and young people in England: cross sectional survey. Arch Dis Child 89: 30-36

23. Stanton B, Cole M, Galbraith J et al (2004) Randomized trial of a parent intervention: parents can make a difference in long-term adolescent risk behaviors, perceptions, and knowledge. Arch Pediatr Adolesc Med 158:947-955

24. Struif E, Mulder M, Pleiver C (2005) Overweight in children of 2 4 years in Zaanstreek, Waterland (in Dutch). Evean, Youth Health Care Division, Purmerend

25. Visscher TLS, Viet AL, van den Brink CL (2007) How many people are overweight or underweight? (in Dutch). In: Volksgezondheid Toekomst Verkenning, Nationaal Kompas Volksgezondheid. RIVM, Bilthoven

26. Waardenberg CM (2005) Nutrition and physical activity in toddlers (in Dutch). GGD West-Friesland, Hoorn

27. de Wilde RA (2003) Prevalence and risk factors of overweight in school-children in the multi-ethnic population of The Hague (in Dutch). TNO-PG, Leiden 